\title{
Mucormycosis in COVID-19 patients: predisposing factors, prevention and management
}

\author{
Pavan Kumar Rudrabhatla ${ }^{1}\left[\right.$ ] $\cdot$ Aravind Reghukumar ${ }^{2} \cdot$ Sanjeev V. Thomas ${ }^{1}$
}

Received: 27 August 2021 / Accepted: 5 November 2021 / Published online: 24 November 2021

(c) Belgian Neurological Society 2021

\begin{abstract}
India is considered the diabetes capital of the world and has the highest burden of mucormycosis. Bacterial, viral and fungal co-infections are increasingly being reported in severe acute respiratory syndrome virus 2 (SARSCoV-2) infected patients. India is one of the worst affected countries during the second wave of the COVID-19 pandemic. This combination of diabetes mellitus, COVID-19 and mucormycosis has led to the drastic upsurge of COVID-19-associated mucormycosis $(\mathrm{CAM})$ in India. Immunosuppression, iron disequilibrium, endothelial injury, ketoacidosis and hypoxia are some of the other COVID-19-related risk factors for CAM. There has been an increase in the proportion of mucormycosis affecting paranasal sinuses and central nervous system (CNS) in CAM compared to pre-COVID-19 literature due to the SARSCoV-2-related pathophysiological mechanisms, complications and treatment strategies. CAM is a medical and surgical emergency, and it can present with non-specific symptoms and signs initially resulting in diagnostic delay. High index of suspicion and regular screening for features of CAM are of paramount importance to prevent lethal consequences. Rapid action with a tripod approach consisting of withdrawal of immunomodulators, early antifungal therapy and extensive surgical debridement is considered the best possible treatment model. We review the published data to give a detailed account of the predisposing factors and their mechanisms, diagnostic work-up, treatment modalities and prevention strategies of CAM with special emphasis on CNS mucormycosis.
\end{abstract}

Keywords Mucormycosis · COVID-19 · Fungal infection · Diabetes mellitus · Immunosuppression · Amphotericin · Surgical debridement

\section{Key Messages}

SARSCoV-2 related pathophysiological mechanisms, complications and treatment strategies can predispose patients to infection with mucormycosis, predominantly affecting paranasal sinuses and CNS.
Hyperglycemia, ketoacidosis, blunted immune response, iron disequilibrium, endothelial injury, irrational use of antibiotics and immunomodulators are the major contributing factors.

Early diagnosis, aggressive medical and surgical management are critical to reduce morbidity and mortality.
Pavan Kumar Rudrabhatla

pavankumarrudrabhatla@gmail.com

Aravind Reghukumar

draravind13@gmail.com

Sanjeev V. Thomas

sanjeev.v.thomas@gmail.com

1 Department of Neurology, Sree Chitra Tirunal Institute for Medical Sciences and Technology, Thiruvananthapuram, India

2 Department of Infectious Diseases, Government Medical College, Thiruvananthapuram, India

\section{Introduction}

The coronavirus disease 2019 (COVID-19) pandemic, caused by severe acute respiratory syndrome virus 2 (SAR$\mathrm{SCoV}-2$ ) since its origin in Wuhan has affected more than 189 million people worldwide, accounting for over 4 million deaths by July 2021 . India is one of the worst affected countries, especially by the second wave of the pandemic. The lockdown policies, declining demand and supply for goods and services in addition to increased health-care consumption have led to a global economic crisis [1]. Many treatment 
decisions, especially concerning the patients hospitalized with COVID-19, have been made based on limited clinical experience and scientific evidence. Antibiotic therapy in patients with COVID-19 was one such clinical decision. Bacterial, viral, or fungal co-infections are described with COVID-19 even though not to the same extent as that in pandemics caused by influenza viruses [2, 3]. Invasive fungal infections were reported in multiple studies $[4,5]$ with an incidence of up to $25 \%$ in critically ill patients with moderate to severe acute respiratory distress syndrome (ARDS) caused by SARSCoV-2 [6]. There has been a surge in mucormycosis in patients affected by COVID-19, leading to disabling morbidity, mortality and an additional burden on health economy. We discuss the predisposing factors, potential steps for prevention and treatment aspects of COVIDassociated mucormycosis (CAM).

\section{Mucormycosis and COVID-19}

Mucormycosis is an angioinvasive fungal infection, with high morbidity and mortality caused by Mucormycetes which belongs to the order Mucorales and class Zygomycetes. Mucorales are thermotolerant saprophytic fungi found in decaying organic matter and soil samples. Pathogenic species such as Rhizopus, Lichtheimia, Cunninghamella, Rhizomucor and Apophysomyces were documented to be isolated in Indian soils [7]. The fungal spores can gain entry through inhalation, ingestion of contaminated food, or abraded skin resulting in rhino-orbito-cerebral, pulmonary, gastrointestinal, or cutaneous/wound infections [8, 9]. Rhino-orbito-cerebral mucormycosis (ROCM) is the most common form of the disease in India, followed by the pulmonary and cutaneous types. Rhizopus oryzae is the most common type, responsible for nearly $60 \%$ of mucormycosis cases in humans and $90 \%$ of the ROCM form $[10,11]$. In ROCM, nasal turbinates are the initial sites to be affected. In a host with intact immune system, the ciliary system helps in the elimination of the spores and phagocytosis can effectively limit the infection and invasion. In an immunodeficient host with inadequate phagocytosis, the spores can germinate into hyphae and invade the vasculature resulting in tissue infarction and necrosis involving the palate, orbit and brain due to contiguous spread [12].

The global prevalence of mucormycosis ranges from 0.005 to 1.7 per million population, while its prevalence in India is nearly 80 times higher $(0.14$ per 1000$)$ compared to developed countries, making India the country with the highest burden of mucormycosis [13-15]. It constituted $2.7 \%$ of all the fungal infections affecting central nervous system (CNS), treated at a tertiary care center in South India [16]. There are increasing reports of rhino-orbital mucormycosis in people with COVID-19, especially in India, in addition to several anecdotal reports in the print and electronic media [17]. These findings are of immense importance considering the very high case fatality rate, especially with intracranial involvement of mucormycosis, reaching up to $90 \%$ [18]. The initial clinical manifestations are often non-specific compounded with early rapid dissemination and clinical worsening, making early clinical suspicion and diagnosis valuable. Nearly $50 \%$ of cases of mucormycosis have been historically diagnosed only in the post-mortem autopsy series, suggesting that even a delay of 12 hours in the diagnosis could be fatal [19]. Susceptible COVID-19 patients should be screened regularly for features like headache, nasal obstruction (especially if persistent or severe and not responding to pain medicines), nasal crusting, nasal discharge which could be brownish or blood tinged, pain, loss of sensation or discolouration of skin over the face, localised facial puffiness, loosening of teeth, discoloration or ulceration of the palate, eye pain, swelling or redness, double vision or loss of vision and drooping of eyelid.

\section{Predisposing factors}

Mucormycosis is rarely reported in healthy individuals; it is predisposed by comorbidities such as diabetes mellitus, organ transplantation, malignancies (especially hematological), immunosuppressive therapy including corticosteroids, prolonged neutropenia, iron overload, chronic antibiotic use, severe burns, intravenous drug abuse and malnutrition, leading to immunocompromise [20]. Some of these factors are particularly relevant in patients with COVID-19 due to its pathophysiological mechanisms and treatment measures.

\section{Diabetes mellitus (DM)}

India is considered as the diabetes capital of the world with around 77 million adults affected [21]. Poorly controlled DM increases the risk of infections due to its effect on host immunological response with significantly increased hospitalization and mortality rates [22]. Mucormycosis is reported to be higher in patients with severe COVID-19 infection and both are predisposed by DM. The presence of DM was associated with increased severity of COVID-19 infection and higher mortality $[6,23]$. SARSCoV-2 infects the host by tropism to host angiotensin-converting enzyme-2 (ACE2) receptor. Increased ACE2 receptor expression, hyperglycemia favoring SARSCoV-2 replication, dysregulated immune response, coagulopathy, and alveolar and endothelial dysfunction are some of the pathological mechanisms noted in DM resulting in severe infection [24]. Overexpression of GRP78 (glucose-regulated protein), augmented availability of micronutrients, diminished defense mechanisms, and acidic environment (especially in diabetic ketoacidosis 
[DKA]) with increased availability of iron for the pathogen make DM the most common risk factor (noted in 54-76\% of cases) for mucormycosis. Overexpression of GRP78 is noted specifically in nasal epithelial cells, which can explain the occurrence of ROCM more in patients with DM than those without $[9,25,26]$. Studies in the context of DKA have shown that $\mathrm{CotH} 3$ (a protein kinase expressed during sporulation) is mainly expressed in the germinations of Rhizopus oryzae. CotH3 has a greater ability to adhere and invade endothelial and nasal epithelial cells compared to other $\operatorname{CotH}[26]$.

Systemic reviews have shown that most of the reported cases of mucormycosis in patients with COVID-19 are from India (70-80\%), which is not surprising considering the burden of mucormycosis and DM in India [17, 27]. Hyperglycemia at presentation was the single most important risk factor observed in $83.3 \%$ of the patients with mucormycosis and COVID-19, pre-existing DM in $80 \%$ and concomitant DKA in $15 \%$ [17]. Studies have shown that SARSCoV-1 can damage pancreatic islets and result in acute diabetes and DKA [28]. There is also evidence for long-term damage to pancreatic beta-cells by SARSCoV-2 as suggested by the persistence of hyperglycemia and occurrence of DKA long after recovery $[29,30]$. A UK study has shown that prevalence of DM and DKA are higher in patients with COVID-19 compared to the general population [31]. Insulin resistance due to cytokine storm and damage to pancreatic islets caused by SARSCoV-2 in addition to use of corticosteroids appear to be the possible explanation for this hyperglycemic state [32].

\section{Blunted immune responses}

In addition to DM, several other factors affect the defense mechanisms against opportunistic infections in patients with COVID-19. Lymphocytopenia has been described in severe cases of COVID-19, and it has been hypothesized that the pathological pathway of SARSCoV-2 predominantly affects T cells $(C D 4+$ and CD8 +) [33]. Cell-mediated immunity involving Mucorales specific T cells plays an important role in controlling invasive infection through various cytokines (interleukin [IL] 4, IL-10, IL-17 and interferon-gamma) that damage the fungal hyphae, indicating that severe COVID-19 infection by itself is a risk factor for invasive mucormycosis.

Immunomodulators including corticosteroids, monoclonal antibodies against IL-6 receptor such as tocilizumab and sotrovimab, and JAK inhibitors such as baricitinib and tofacitinib are used in the treatment of moderate to severe COVID-19 infections to blunt the exaggerated immune response [34-36]. The frequent use of immunosuppressants along with other predisposing factors provide an ideal environment for invasive fungal infections. In addition, corticosteroids can affect glucose homeostasis resulting in uncontrolled hyperglycemia and precipitation of DKA.
Ketoacidosis creates an ideal environment for germination of fungal spores and reduced cell-mediated immune responses (phagocytic activity), both due to corticosteroids and hyperglycaemic state, further worsen the situation resulting in invasive mucormycosis [24, 37].

\section{Iron disequilibrium and role of zinc excess}

Severe COVID-19 infection is characterized by excessive release of cytokines and a hyperferritinemic state. Excessive ferritin synthesis along with reduced extracellular iron transport results in high levels of intracellular iron [38]. Patients with DKA also have elevated levels of free iron in serum, probably due to the release of iron from binding proteins (like transferrin) in the presence of acidosis [37]. Elevated intracellular iron levels in turn produce excessive reactive oxygen species which cause tissue damage and release of free iron into the circulation. The acidic state can be further worsened by renal dysfunction and hypoxia which are common in hospitalized patients with COVID-19 [39]. Evidence shows that elevated levels of serum free iron levels and low levels of dialyzable inhibitory factor in diabetics are suitable conditions for fungal replication. Hence, the acidic milieu (which is the overall effect of multiple factors) forms an ideal environment for fungal proliferation due to the availability of free iron which is required for cell growth and development [37, 40, 41].

Zinc-binding proteins act as transcription factors for biological processes responsible for fungal growth and studies have shown that zinc starvation induces biological stress and inhibits fungal proliferation [42, 43]. Use of micronutrient supplements, including zinc as possible immune boosters has increased in the COVID-19 era, which can contribute to the increased cases of mucormycosis.

\section{Endothelial injury}

Endothelialitis and endothelial damage noted in severe COVID-19 forms another possible explanation for increased incidence of mucormycosis. Pulmonary vascular endothelial cells express ACE2 receptors and endothelialitis can be solely immune mediated or due to an immune response secondary to direct viral infection. Autopsy reports in COVID-19 patients have shown severe endothelial injury with disrupted cell membranes, widespread thrombosis, microangiopathy and angiogenesis in pulmonary vasculature along with the presence of intracellular virus [44, 45]. Endothelial adhesion and penetration are critical in the early stages of infection in mucormycosis [41]. Glucose-regulated protein (GRP 78) and the Mucorales adhesin spore coat protein homologs $(\mathrm{CotH})$ are endothelial receptors which facilitate the endothelial adhesion in mucormycosis. Acidosis and 
hyperglycemic states induce the expression of these receptors, further worsening the situation [41, 46].

Excessive and irrational use of antibiotics in patients with COVID-19 is underreported. An interrupted time series analyses of sales volumes of antibiotics in India estimated that COVID-19 likely contributed to 216.4 million excess doses of antibiotics and 38.0 million excess doses of azithromycin until the peak of the first pandemic wave [47]. Chronic antibiotic use by itself is a risk factor for opportunistic fungal infections including mucormycosis and irrational use can result in emergence of antimicrobial resistance [48]. A study performed at a tertiary care center in South India compared the risk factors among CAM and nonCOVID mucor patients. Most patients (76.7\%) with CAM had mild COVID-19. DM was a significant risk factor in both groups, whereas uncontrolled DM and newly detected DM were more common among CAM group. Unwarranted steroid use and elevated serum ferritin levels were found to be significantly higher in CAM patients [49].

Mucormycosis of oronasal cavity or paranasal sinuses can present with symptoms of sinusitis or periorbital cellulitis, facial numbness, conjunctival suffusion, visual blurring, and soft tissue swelling followed by eschar formation and necrosis. Paranasal sinuses are the most common site affected by mucormycosis [50] and the proportion of patients with involvement of paranasal sinuses and CNS has increased in COVID-19-associated mucormycosis compared to preCOVID studies (Table 1) [17, 51]; this is probably due to pathophysiological mechanisms and complications of SARSCoV-2.

\section{Central nervous system infection}

\section{Incidence and modes of spread}

CNS mucormycosis is the third most common site of infection after paranasal sinuses and orbit in the Indian population where DM is the most important risk factor [50]. In a study by Roden et al., DM and injection drug abuse were found to be the most important risk factors for CNS

Table 1 Comparison of the locations of mucormycosis involvement in the non-COVID and COVID-19 patient groups

\begin{tabular}{lll}
\hline $\begin{array}{l}\text { Location of mucor- } \\
\text { mycosis }\end{array}$ & $\begin{array}{l}\text { Roden et al. [51] (non- } \\
\text { COVID) (\%) }\end{array}$ & $\begin{array}{l}\text { Singh et al. [17] } \\
\text { (COVID) (\%) }\end{array}$ \\
\hline Sinuses & $\mathbf{3 9}$ & $\mathbf{8 8 . 9}$ \\
Cerebral & $\mathbf{9}$ & $\mathbf{2 2 . 2}$ \\
Pulmonary & 24 & 7.9 \\
Cutaneous & 19 & 1 \\
\hline
\end{tabular}

Bold signifies increase in the COVID group compared to the nonCOVID group of patients mucormycosis. Of 337 mucormycosis patients with DM, $66 \%$ had disease of the paranasal sinuses, and $43 \%$ of these had cerebral extension [51]. CNS involvement occurs most commonly due to contiguous spread from paranasal sinuses or orbit $(70 \%)$; other modes include hematogenous spread or direct inoculation (surgery, penetrating trauma, lumbar puncture, epidural injection) [51].

\section{Clinical presentation}

CNS mucormycosis can present with features of meningitis, cranial neuropathies (predominantly ophthalmoplegia), other focal neurological deficits and/or features of raised intracranial pressure [52]. Cavernous sinus can be involved, particularly in the course of ROCM leading to thrombosis and cranial nerve dysfunction. Hemiparesis, dysarthria, altered sensorium and focal seizures indicate invasion of brain parenchyma resulting in granulomatous lesions, abscess formation or stroke due to angioinvasion [52-55].

\section{Imaging features}

Frequent imaging findings in intracranial mucormycosis include cavernous sinus thrombosis, brain infarction, internal carotid artery occlusion, and parenchymal lesions (granulomatous and abscesses). Lesions may be either hypoor hyperintense on T2-weighted sequences and diffusionweighted imaging (DWI) sequences show reduced diffusion $[56,57]$. Granulomatous lesions are usually noted in the frontal lobes and affinity of mucormycosis for basal ganglia with abscess formation has been reported in intravenous drug abusers [54, 55].

\section{Diagnosis}

The initial symptoms in mucormycosis can be non-specific and can be erroneously attributed to COVID-19 disease itself. There must be a high index of suspicion, especially in patients with predisposing factors. Early warning signs and symptoms should not be missed, as delay in treatment can be fatal.

Laboratory investigations can help to detect hyperglycemia, ketoacidosis, neutropenia, dyselectrolytemia and iron overload states. Computed tomography (CT) scan of the head can show the nature and extent of involvement of the soft tissue structures, sinuses, orbit and brain. Imaging should be thoroughly examined for mucosal thickening and opacification of the sinuses, edema, inflammation and infarcts in the brain, bony erosion and necrosis. Contrastenhanced CT scan can detect cavernous sinus thrombosis and can show enhancement of vessels. Magnetic resonance imaging (MRI) is an inherently multiplanar imaging 
modality, which has excellent soft tissue contrast resolution and is more helpful in clearly delineating early vascular invasion and perineural and intracranial spread, especially using T2-weighted fat-suppressed and short-T1inversion recovery (STIR) sequences. MRI permits detection of imaging signs, which are difficult to demonstrate on CT such as cavernous sinus involvement, vascular invasion, perineural spread, optic nerve infarction, and differentiation of cerebral parenchymal invasion from infarction with better visualization of periantral and infratemporal fossa extension, orbital soft tissue involvement, and skull base invasion [58]. A retrospective case-control study has shown that MRI was more sensitive than CT ( $85 \%$ vs $57 \%$ ) for the diagnosis of acute fulminant invasive fungal sinusitis [59]. Contrast-enhanced MRI is considered the imaging modality of choice, as it can help delineate the necrotic tissue to guide the extent of resection [60].

Biopsy should be considered if mucormycosis is the potential diagnosis and definite diagnosis is ascertained by the demonstration of the characteristic non-septate or pauciseptate, irregularly branching ribbon-shaped hyphae in the tissue specimens (can even be demonstrated by microscopic examination of specimen in $\mathrm{KOH}$ [potassium hydroxide] wet mount preparation). Culture of specimens is recommended for genus and species recognition. Polymerase chain reaction (PCR) amplification and sequencing were first applied to better identify isolates that were grown from cultures of biopsies or bronchoalveolar lavage samples [61]. Matrixassisted laser desorption ionization-time of flight (MALDITOF) mass spectrometry is a molecular technique used to identify Mucorales from cultures [62]. Internal transcribed spacer (ITS) sequencing has been proposed as a valuable target for resolution to genus and usually to the species level by the Clinical and Laboratory Standards Institute (CLSI) guidelines for fungal identification [63]. Recently, noninvasive PCR-based procedures have been used to detect Mucorales DNA in samples, such as plasma, serum or urine. These techniques can be performed in any patient; they help to anticipate the diagnosis of mucormycosis, distinguish between Aspergillus and Mucorales infections very early thereby improving patient outcome [64]; elevated serum galactomannan can help to differentiate invasive aspergillosis from mucormycosis [65].

\section{Treatment}

Mucormycosis is a medical as well as surgical emergency and requires rapid action. Empirical antifungal medication and surgical debridement should be considered early in the course of infection in potential cases of ROCM based on risk factors, clinical features and imaging findings. No guidelines are available for management of mucormycosis in COVID-19 patients; the guidelines for mucormycosis are usually adopted with individualized modifications [61]. A tripartite approach is usually adopted consisting of reversal of the immunosuppressive state, administration of antifungal medication and extensive surgical debridement.

It is prudent to withdraw immunosuppressive medication in patients with COVID-19 and mucormycosis considering their devastating consequences. Other metabolic abnormalities that contribute to immunosuppressive state including hyperglycemia, acidosis, dyselectrolytemia and hypoxia should be corrected. Granulocyte colony-stimulating factor can be considered in case of leucopenia to boost the immune response.

Intravenous liposomal amphotericin B at a dose of $10 \mathrm{mg} /$ $\mathrm{kg}$ /day is the first-line antifungal agent of choice for monotherapy of CNS mucormycosis, with full dose from day- 1 . In case of renal dysfunction, which is common in severe COVID-19 patients with multiple organ dysfunction syndrome (MODS), dose modification is not needed but the timing of administration of liposomal amphotericin B in relation to any form of renal replacement therapy should be decided based on nephrology opinion [39]. However, a dose of less than $5 \mathrm{mg} / \mathrm{kg} /$ day has only a marginal supporting evidence. In the absence of CNS involvement, amphotericin B lipid complex ( $5 \mathrm{mg} / \mathrm{kg} /$ day) can also be considered. Other antifungal medications include intravenous isavuconazole $(3 \times 200 \mathrm{mg}$ on day $1-2,1 \times 200 \mathrm{mg}$ per day from day 3$)$, intravenous posaconazole $(2 \times 300 \mathrm{mg}$ on day $1,1 \times 300 \mathrm{mg}$ per day from day 2), and posaconazole oral suspension ( $4 \times 200 \mathrm{mg}$ per day), which can be considered in case of renal dysfunction as an alternative to liposomal amphotericin B, or as an add-on in progressive disease as part of salvage therapy. They can also be started in combination with liposomal amphotericin B in case of extensive disease, rapid progression, or poor general condition. Although effective, the use of amphotericin B deoxycholate is limited by its adverse effects and should only be considered when no other antifungals are available. Maintenance therapy with isavuconazole or posaconazole can be considered once the disease is stabilized. Treatment should be continued till complete reversal of immunosuppression and resolution of disease as suggested by imaging [61]. Availability of antifungal medication and affordability issues significantly affect the therapy in developing countries in addition to comorbidities like renal dysfunction.

As amphotericin cannot attain therapeutic concentrations in necrotic tissue, whenever possible, early extensive surgical debridement or resection should be performed in mucormycosis, which is the key for disease control and helps in histopathological and microbiological diagnosis [61]. Hyperbaric oxygen therapy is expected to improve hypoxia and acidosis, thereby restricting fungal multiplication; however, its role is yet to be established [66]. 
In a review of 929 patients with zygomycosis, $64 \%$ were treated with some form of antifungal chemotherapy with a survival rate of $62 \%$ (369 of 596 patients). The survival rates of patients treated with surgery alone was $57 \%$ and for those treated with a combination of surgery and antifungal chemotherapy $70 \%$; survival rate was only $3 \%$ when no treatment was received [51].

\section{Steps for prevention of mucormycosis in patients with COVID-19}

- A detailed history regarding the medical comorbidities (DM, organ transplantation, malignancies) can help in fine-tuning the treatment and reduce the risk of opportunistic infections.

- Knowledge about patient's current medications (including immunosuppressants) is crucial for medical reconciliation and prevention of additional immunosuppression.

- Corticosteroids and other immunomodulators should be used judiciously with right timing at the evidence-based dose and for the recommended duration.

- Irrational use of antibiotics should be avoided.

- Strict monitoring of blood glucose levels in admitted as well as discharged patients and prompt correction are critical.

- Use of insulin is prudent in patients with DM admitted for treatment of COVID-19.

- There should be a constant vigil to detect risk factors such as DKA, acidosis, hypoxia, and leucopenia and necessary steps should be initiated immediately for their correction.

- Use of clean sterile water in humidifiers can reduce the risk of infection.

\section{Conclusion}

Mucormycosis is an angioinvasive fungal infection increasingly being reported in patients with COVID-19. Irrational use of immunosuppressants (corticosteroids in particular) and antibiotics, hyperglycemia, acidosis, hypoxia, iron disequilibrium and endothelial injury are some of the important risk factors for mucormycosis in the setting of COVID-19 pandemic. A high degree of suspicion is a must for early diagnosis and prompt treatment to reduce morbidity and mortality. Reversal of immunosuppressive state, correction of metabolic parameters, administration of antifungal medication and early aggressive surgical debridement are the recommended management strategies.
Author contributions PKR: literature search, data analysis, writing original draft. AR: critical review and editing. SVT: idea of the article, critical revision.

Funding The authors received no financial support for the research, authorship, and/or publication of this article.

\section{Declarations}

Conflict of interest The authors declare that there are no conflicts of interest related to the subject matter or materials discussed in this article.

Ethical approval This article does not contain any studies with human participants (or animal) by any of the authors.

\section{References}

1. Tandon A, Roubal T, McDonald L, Cowley P, Palu T, de Oliveira Cruz V et al (2020) Economic impact of COVID-19: implications for health financing in Asia and Pacific. Health, Nutrition and Population Discussion Paper, World Bank, Washington, DC. (C) World Bank

2. Lansbury L, Lim B, Baskaran V, Lim WS (2020) Co-infections in people with COVID-19: a systematic review and meta-analysis. J Infect 81(2):266-275. https://doi.org/10.1016/j.jinf.2020.05.046

3. Garcia-Vidal C, Sanjuan G, Moreno-García E, Puerta-Alcalde P, Garcia-Pouton N, Chumbita M et al (2021) Incidence of co-infections and superinfections in hospitalized patients with COVID-19: a retrospective cohort study. Clin Microbiol Infect 27(1):83-88. https://doi.org/10.1016/j.cmi.2020.07.041

4. Chen N, Zhou M, Dong X, Qu J, Gong F, Han Y et al (2020) Epidemiological and clinical characteristics of 99 cases of 2019 novel coronavirus pneumonia in Wuhan, China: a descriptive study. Lancet 395(10223):507-513. https://doi.org/10.1016/ S0140-6736(20)30211-7

5. van Arkel ALE, Rijpstra TA, Belderbos HNA, van Wijngaarden P, Verweij PE, Bentvelsen RG (2020) COVID-19 associated pulmonary aspergillosis. Am J Respir Crit Care Med. https://doi.org/ 10.1164/rccm.202004-1038LE

6. Koehler P, Cornely OA, Bottiger BW, Dusse F, EichenauerDA FF et al (2020) COVID-19 associated pulmonary aspergillosis. Mycoses. https://doi.org/10.1111/myc.13096

7. Prakash H, Ghosh AK, Rudramurthy SM, Paul RA, Gupta S, Negi V et al (2016) The environmental source of emerging Apophysomyces variabilis infection in India. Med Mycol 54:567-575. https://doi.org/10.1093/mmy/myw014

8. Roden MM, Zaoutis TE, Buchanan WL, Knudsen TA, Sarkisova TA, Schaufele RL et al (2005) Epidemiology and outcome of zygomycosis: a review of 929 reported cases. Clin Infect Dis 41:634-653. https://doi.org/10.1086/432579

9. Jeong W, Keighley C, Wolfe R, Lee WL, Slavin MA, Kong DCM et al (2019) The epidemiology and clinical manifestations of mucormycosis: a systematic review and meta-analysis of case reports. Clin Microbiol Infect 25:26-34. https://doi.org/10.1016/j. cmi.2018.07.011

10. Prakash H, Ghosh AK, Rudramurthy SM, Singh P, Xess I, Savio J et al (2019) A prospective multicenter study on mucormycosis in India: epidemiology, diagnosis, and treatment. Med Mycol 57:395-402. https://doi.org/10.3390/jof6040265

11. Patel A, Kaur H, Xess I, Michael JS, Savio J, Rudramurthy S et al (2020) A multi-centre observational study on the epidemiology, 
risk factors, management and outcomes of mucormycosis in India. Clin Microbiol Infect 26(944):e9-944.e15. https://doi.org/10. 1016/j.cmi.2019.11.021

12. Frater JL, Hall GS, Procop GW (2001) Histologic features of zygomycosis: emphasis on perineural invasion and fungal morphology. Arch Pathol Lab Med 125:375-378. https://doi.org/10. 5858/2001-125-0375-HFOZ

13. Skiada A, Pavleas I, Drogari-Apiranthitou M (2020) Epidemiology and diagnosis of mucormycosis: an update. J Fungi (Basel) 6(4):265. https://doi.org/10.3390/jof6040265

14. Chander J, Kaur M, Singla N, Punia RPS, Singhal SK, Attri AK et al (2018) Mucormycosis: battle with the deadly enemy over a five-year period in India. J Fungi (Basel) 4(2):46. https://doi.org/ 10.3390/jof4020046

15. Prakash H, Chakrabarti A (2019) Global epidemiology of mucormycosis. J Fungi (Basel) 5(1):26. https://doi.org/10.3390/jof50 10026

16. Ramesha KN, Kate MP, Kesavadas C, Radhakrishnan VV, Nair S, Thomas SV (2010) Fungal infections of the central nervous system in HIV-negative patients: experience from a tertiary referral center of South India. Ann Indian Acad Neurol 13(2):112-116. https://doi.org/10.4103/0972-2327.64635

17. Singh AK, Singh R, Joshi SR, Misra A (2021) Mucormycosis in COVID-19: A systematic review of cases reported worldwide and in India. Diabetes Metab Syndr Clin Res Rev. https://doi.org/10. 1016/j.dsx.2021.05.019 (Internet)

18. Deutsch PG, Whittaker J, Prasad S (2019) Invasive and non-invasive fungal rhinosinusitis - a review and update of the evidence. Medicina 55:1-14. https://doi.org/10.3390/medicina55070319

19. Maartens G, Wood MJ (1991) The clinical presentation and diagnosis of invasive fungal infections. J Antimicrob Chemother 28(Suppl A):13-22, 17-44. https://doi.org/10.1093/jac/28. suppl_a.13

20. Sugar AM (1992) Mucormycosis. Clin Infect Dis 14:S126-S129. https://doi.org/10.1093/clinids/14.supplement_1.s126

21. International Diabetes Federation (ed) (2019) IDF diabetes Atlas, 9th edn. International Diabetes Federation, Brussels

22. Mor A, Dekkers OM, Nielsen JS, Beck-Nielsen H, Sorensen HT, Thomsen RW (2017) Impact of glycemic control on risk of infections in patients with type 2 diabetes: a population-based cohort study. Am J Epidemiol 186(2):227-236. https://doi.org/10.1093/ aje/kwx049

23. Apicella M, Campopiano MC, Mantuano M, Mazoni L, Coppelli A, Del Prato S (2020) COVID-19 in people with diabetes: understanding the reasons for worse outcomes. Lancet Diabetes Endocrinol 8(9):782-792. https://doi.org/10.1016/S2213-8587(20) 30238-2

24. Erener S (2020) Diabetes, infection risk and COVID-19. Mol Metab 39:101044. https://doi.org/10.1016/j.molmet.2020.101044

25. Prakash H, Chakrabarti A (2021) Epidemiology of mucormycosis in India. Microorganisms 9(3):523. https://doi.org/10.3390/micro organisms 9030523

26. Morales-Franco B, Nava-Villalba M, Medina-Guerrero EO, Sánchez-Nuño YA, Davila-Villa P, Anaya-Ambriz EJ et al (2021) Host-pathogen molecular factors contribute to the pathogenesis of Rhizopus spp. in diabetes mellitus. Curr Trop Med Rep 8:1-12. https://doi.org/10.1007/s40475-020-00222-1

27. John TM, Jacob CN, Kontoyiannis DP (2021) When uncontrolled diabetes mellitus and severe COVID-19 converge: the perfect storm for mucormycosis. J Fungi (Basel) 7(4):298. https://doi. org/10.3390/jof7040298 (Published 2021 Apr 15)

28. Yang JK, Lin SS, Ji XJ, Guo LM (2010) Binding of SARS coronavirus to its receptor damages islets and causes acute diabetes. Acta Diabetol 47:193-199. https://doi.org/10.1007/s00592-009-0109-4

29. Potier L, Julla JB, Roussel R, Boudou P, Gauthier DC, Ketfi $\mathrm{C}$ et al (2021) COVID-19 symptoms masking inaugural ketoacidosis of type 1 diabetes. Diabetes Metab 47(1):101162. https://doi.org/10.1016/j.diabet.2020.05.004

30. Marchand L, Pecquet M, Luyton C (2020) Type 1 diabetes onset triggered by COVID-19. Acta Diabetol 57(10):1265-1266. https://doi.org/10.1007/s00592-020-01570-0

31. Goldman N, Fink D, Cai J, Lee YN, Davies Z (2020) High prevalence of COVID-19-associated diabetic ketoacidosis in UK secondary care. Diabetes Res Clin Pract 166:108291. https:// doi.org/10.1016/j.diabres.2020.108291

32. Kothandaraman N, Rengaraj A, Xue B, Yew WS, Velan SS, Karnani $\mathrm{N}$ et al (2021) COVID-19 endocrinopathy with hindsight from SARS. Am J Physiol Endocrinol Metab 320:E139-E150. https://doi.org/10.1152/ajpendo.00480.2020

33. Pasero D, Sanna S, Liperi C, Piredda D, Branca GP, Casadio L et al (2020) A challenging complication following SARS-CoV-2 infection: a case of pulmonary mucormycosis. Infection 17:1-6. https://doi.org/10.1007/s15010-020-01561-x

34. RECOVERY Collaborative Group, Horby P, Lim WS, Emberson JR, Mafham M, Bell JL, Linsell L et al (2021) Dexamethasone in hospitalized patients with Covid-19. N Engl J Med 384(8):693-704. https://doi.org/10.1056/NEJMoa2021436

35. Diurno F, Numis FG, Porta G, Cirillo F, Maddaluno S, Ragozzino A et al (2020) Eculizumab treatment in patients with COVID-19: preliminary results from real life ASL Napoli 2 Nord experience. Eur Rev Med Pharmacol Sci 24(7):4040 4047. https://doi.org/10.26355/eurrev_202004_20875

36. Salama C, Han J, Yau L, Reiss WG, Kramer B, Neidhart JD et al (2021) Tocilizumab in patients hospitalized with Covid19 pneumonia. N Engl J Med 384(1):20-30. https://doi.org/10. 1056/NEJMoa2030340

37. Artis WM, Fountain JA, Delcher HK, Jones HE (1982) A mechanism of susceptibility to mucormycosis in diabetic ketoacidosis: transferrin and iron availability. Diabetes 31(12):11091114. https://doi.org/10.2337/diacare.31.12.1109

38. Perricone C, Bartoloni E, Bursi R, Cafaro G, Guidelli GM, Shoenfeld Y et al (2020) COVID-19 as part of the hyperferritinemic syndromes: the role of iron depletion therapy. Immunol Res 68:213-224. https://doi.org/10.1007/s12026-020-09145-5

39. Chan L, Chaudhary K, Saha A, Chauhan K, Vaid A, Zhao S et al (2021) AKI in hospitalized patients with COVID-19. JASN 32(1):151-160. https://doi.org/10.1681/ASN.2020050615

40. Cohen SG, Greenberg MS (1980) Rhinomaxillary mucormycosis in a kidney transplant patient. Oral Surg Oral Med Oral Pathol 50(1):33-38. https://doi.org/10.4103/0973-029X.140765

41. Ibrahim AS, Spellberg B, Walsh TJ, Kontoyiannis DP (2012) Pathogenesis of mucormycosis. Clin Infect Dis 54(Suppl 1):S16-S22. https://doi.org/10.1093/cid/cir865

42. Staats CC, Kmetzsch L, Schrank A, Vainstein MH (2013) Fungal zinc metabolism and its connections to virulence. Front Cell Infect Microbiol 14(3):65. https://doi.org/10.3389/fcimb.2013. 00065

43. Eide DJ (2011) The oxidative stress of zinc deficiency. Metallomics 3(11):1124-1129. https://doi.org/10.1039/c1mt00064k

44. Ackermann M, Verleden SE, Kuehnel M, Haverich A, Welte T, Laenger $F$ et al (2020) Pulmonary vascular endothelialitis, thrombosis, and angiogenesis in Covid-19. N Engl J Med 383(2):120 128. https://doi.org/10.1056/NEJMoa2015432

45. Varga Z, Flammer AJ, Steiger P, Haberecker M, Andermatt $\mathrm{R}$, Zinkernagel AS et al (2020) Endothelial cell infection and endotheliitis in COVID-19. Lancet 395:1417-1418. https://doi. org/10.1016/S0140-6736(20)30937-5

46. Sabirli R, Koseler A, Goren T, Turkcuer I, Kurt O (2021) High GRP78 levels in Covid-19 infection: a case-control study. Life Sci 265:118781. https://doi.org/10.1016/j.lfs.2020.118781

47. Sulis G, Batomen B, Kotwani A, Pai M, Gandra S (2021) Sales of antibiotics and hydroxychloroquine in India during the 
COVID-19 epidemic: an interrupted time series analysis. PLoS Med 18(7):e1003682. https://doi.org/10.1371/journal.pmed.10036 82

48. Bhanuprasad K, Manesh A, Devasagayam E, Varghese L, Cherian LM, Kurien R, Karthik R, Deodhar D, Vanjare H, Peter J, Michael JS, Thomas M, Samuel P, Varghese GM (2021) Risk factors associated with the mucormycosis epidemic during the COVID-19 pandemic. Int J Infect Dis 111:267-270. https://doi.org/10.1016/j. ijid.2021.08.037

49. Miranda C, Silva V, Capita R, Alonso-Calleja C, Igrejas G, Poeta $P$ (2020) Implications of antibiotics use during the COVID19 pandemic: present and future. J Antimicrob Chemother 75(12):3413-3416. https://doi.org/10.1093/jac/dkaa350

50. Manesh A, Rupali P, Sullivan MO, Mohanraj P, Rupa V, George B et al (2019) Mucormycosis - a clinicoepidemiological review of cases over 10 years. Mycoses 62(4):391-398. https://doi.org/ 10.1111/myc. 12897

51. Roden MM, Zaoutis TE, Buchanan WL, Knudsen TA, Sarkisova TA, Schaufele RL et al (2005) Epidemiology and outcome of zygomycosis: a review of 929 reported cases. Clin Infect Dis 41(5):634-653. https://doi.org/10.1086/432579

52. Chikley A, Ben-Ami R, Kontoyiannis DP (2019) Mucormycosis of the central nervous system. J Fungi (Basel) 5(3):59. https://doi. org/10.3390/jof5030059

53. Mantadakis E, Samonis G (2009) Clinical presentation of zygomycosis. Clin Microbiol Infect 15(Suppl 5):15-20. https://doi.org/ 10.1111/j.1469-0691.2009.02974.x

54. Dubey A, Patwardhan RV, Sampth S, Santosh V, Kolluri S, Nanda A (2005) Intracranial fungal granuloma: analysis of 40 patients and review of the literature. Surg Neurol 63(3):254-260. https:// doi.org/10.1016/j.surneu.2004.04.020 (discussion 260)

55. Hazama A, Galgano M, Fullmer J, Hall W, Chin L (2017) Affinity of mucormycosis for basal ganglia in intravenous drug users: case illustration and review of literature. World Neurosurg 98:872. e1-872.e3. https://doi.org/10.3389/fneur.2020.00295

56. Kursun E, Turunc T, Demiroglu YZ, Aliskan HE, Arslan AH (2015) Evaluation of 28 cases of mucormycosis. Mycoses 58:8287. https://doi.org/10.1111/myc. 12278

57. Horger M, Hebart H, Schimmel H, Vogel M, Brodoefel H, Oechsle $\mathrm{K}$ et al (2006) Disseminated mucormycosis in haematological patients: CT and MRI findings with pathological correlation. $\mathrm{Br}$ J Radiol 79:e88-e95. https://doi.org/10.1259/bjr/16038097

58. Sreshta K, Dave TV, Varma DR, Nair AG, Bothra N, Naik MN, Sistla SK (2021) Magnetic resonance imaging in rhino-orbital-cerebral mucormycosis. Indian J Ophthalmol 69(7):1915-1927. https://doi.org/10.4103/ijo.IJO_1439_21

59. Groppo ER, El-Sayed IH, Aiken AH, Glastonbury CM (2011) Computed tomography and magnetic resonance imaging characteristics of acute invasive fungal sinusitis. Arch Otolaryngol Head Neck Surg 137(10):1005-1010. https://doi.org/10.1001/archoto. 2011.170

60. Sen M, Lahane S, Lahane TP, Parekh R, Honavar SG (2021) Mucor in a viral land: a tale of two pathogens. Indian J Ophthalmol 69(2):244-252. https://doi.org/10.4103/ijo.IJO_3774_20

61. Cornely OA, Alastruey-Izquierdo A, Arenz D, Chen SCA, Dannaoui E, Hochhegger B et al (2019) Global guideline for the diagnosis and management of mucormycosis: an initiative of the European Confederation of Medical Mycology in cooperation with the Mycoses Study Group Education and Research Consortium. Lancet Infect Dis 19(12):e405-e421. https://doi.org/10.1016/ S1473-3099(19)30312-3

62. Cassagne C, Ranque S, Normand AC, Fourquet P, Thiebault S, Planard C et al (2011) Mould routine identification in the clinical laboratory by matrix-assisted laser desorption ionization time-offlight mass spectrometry. PLoS One 6(12):e28425. https://doi.org/ 10.1371/journal.pone.0028425

63. Dannaoui E (2009) Molecular tools for identification of zygomycetes and the diagnosis of zygomycosis. Clin Microbiol Infect 15:66-70. https://doi.org/10.1111/j.1469-0691.2009.02983.x

64. Millon L, Scherer E, Rocchi S, Bellanger A-P (2019) Molecular strategies to diagnose mucormycosis. J Fungi. 5(1):24. https://doi. org/10.3390/jof5010024

65. Cho HJ, Hong SD, Kim HY, Chung SK, Dhong HJ (2016) Clinical implications of serum galactomannan measurement in patients with acute invasive fungal rhinosinusitis. Rhinology 54(4):336341. https://doi.org/10.4193/Rhin15.186

66. Ferguson BJ, Mitchell TG, Moon R, Camporesi EM, Farmer J (1988) Adjunctive hyperbaric oxygen for treatment of rhinocerebral mucormycosis. Rev Infect Dis 10(3):551-559. https://doi. org/10.1093/clinids/10.3.551

Publisher's Note Springer Nature remains neutral with regard to jurisdictional claims in published maps and institutional affiliations. 